\title{
Integrating high resolution remote sensing technology into an advanced water resources knowledge management system
}

\author{
R.A. BRADSHAW ${ }^{1}$, A. JAMES ${ }^{1}$, Y. HEE KHO ${ }^{1}$, D. KASKINA ${ }^{1}$, S. MASHTAYEVA ${ }^{2}$, \\ O. ALIPBEKI ${ }^{3}$ \& Z. MAKSUT ${ }^{3}$
}

1 Nazarbayev University, School of Engineering, Astana, Kazakhstan roland.bradshaw@nu.edu.kz;

2 Eurasian National University, Astana, Kazakhstan

3 National Company 'Kazakhstan Gharysh Sapary', Astana, Kazakhstan

\section{INTRODUCTION}

Information and communication technologies-led growth in remote sensing and image processing has unexplored potential for applications in the management of water resources and environmental systems for monitoring their physical, chemical and biological attributes. This project aims to advance the application of Remote Sensing in the context of managing water resources by integrating high resolution remote sensing technology into a Knowledge Management System for the management of water resources and the infrastructure to control them. Remote sensing technology is used to complement the development of a knowledge management system by advancing the remote sensing capability and image processing to near-real time. This capability can be used to monitor and assess a river basin to develop flood extent and predictions, but also to assess hydrological capacities for hydro-power generation.

\section{HIGH RESOLUTION REMOTE SENSING TECHNOLOGY}

In this project high resolution remote sensing data was procured to develop advanced algorithms that are used for assessing and monitoring water resources in river basin water resource management. The data was provided by the Kazakhstan state company, KGS, from its own remote sensing satellites, KazEOsat-1 and KazEOsat-2, and KGS partners' satellites. KGS performs distribution activities of the satellites within the Astrium-Geoinformation constellation, and additionally the RapidEye constellation. The project uses remote sensing data procured from a high resolution ( $1 \mathrm{~m}$ panchromatic and $4 \mathrm{~m}$ multispectral) remote sensing satellite with the following specifications: PAN: $600 \mathrm{~nm}$, Blue: $455-520 \mathrm{~nm}$, Green: 525-595 nm, Red: 630-695 $\mathrm{nm}$, NIR: $775-850 \mathrm{~nm}$. The middle resolution satellite has a $6.5 \mathrm{~m}$ multispectral resolution with the following bandwidths: Blue: 430-500 nm, Green: 520-590 nm, Red: 630-685 nm, Red-edge: 790-730 nm, NIR: 760-850 $\mathrm{nm}$. Data from both satellites are used to apply algorithms to assess and monitor the hydrology of lakes, rivers and reservoirs for: (1) creating and updating the inventory of water resources, (2) creating and updating the inventory of water bodies, (3) river basins mapping and waterline identification, (4) detection of intermittent streams (streamflow and hollows), (5) mapping of lakes and reservoirs and their major components (edge, coastal slope, coast, coastal shallows), (6) determining the type of lake water cycle in nature (waste, closed drainage, flow, temporary waste, etc.), (7) separation of lakes by mineralization, from relatively fresh to salty, (8) identify the elements of the structure of flood plains of major rivers (bends, meanders, oxbow lakes, etc.), (9) detection and typing of large fluvial forms and their elements (ridge, rolls, reaches, backwaters, etc.), (10) identifying the structure of young floodplain formations (islands, shoals, braids, blind area, etc.), (11) identification of areas of river flooding during flooding, and flood forecasting, (12) delimitation of the flooded areas during floods and a preliminary assessment of the impact of floods, and (13) detection of unauthorized building in flood plains. 


\section{Knowledge management system}

The information obtained with the high resolution remote sensing technology is then integrated into a knowledge management system that was developed as a prototype software platform to contain all relevant information required for water resources decision making and management.

The conceptual water resources knowledge management framework was developed to include nine distinct but interrelated components consisting of: (1) water resource strategy and policy; (2) stakeholder management, (3) ownership, responsibility, authority and resources, (4) inventory of the water resource and its infrastructure, (5) condition and performance of a water resource and its infrastructure, (6) valuations and financial review, (7) monitoring, control and knowledge management, (8) internal process development and review, and (9) risk assessment, management, and emergency response.

In addition to the remote sensing data application layer, the Knowledge Management Platform requires integration of many different technologies and methods including network technology, sensor technology, database technology, telecommunication technology and information management systems, and typically consists of four parts: wireless sensor network, local server, monitoring service platform and application server which are connected and operated coordinately. They form an integral part of real time data collecting, management of information, comprehensive analysis and support planning, and real time control. The algorithms for remote sensing data processing are then embedded into the software script to integrate (near) real-time monitoring and control into a software platform used to manage water resources and their controlling infrastructure. The software and hardware design principle of (near) real-time monitoring and management system in water resources was developed as shown in Fig. 1.

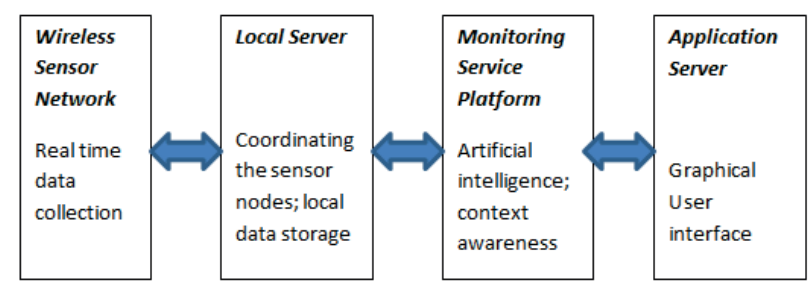

Denotes two-way communication links

Fig. 1 Integrated communication framework.

\section{PROJECT RELEVANT REFERENCES}

Braga, B.P.F. (2001) Integrated urban water resources management: A challenge into the 21st century. International Journal of Water Resources Development 17(4), 581-599.

Chen, C.H. and Ho, P.P. (2008) Statistical pattern recognition in remote sensing. Pattern Recognition 41(9), $2731-2741$.

Dalcanale, F., Fontane, D. and Csapo, J. (2011) A general framework for a collaborative water quality knowledge and information network. Environmental Management 47(3), 443-455.

Hou, J., Mi, W. and Sun, J. (2014) Optimal spatial allocation of water resources based on Pareto ant colony algorithm. International Journal of Geographical Information Science 28(2), 213-233.

Legleiter, C.J., Roberts, D.A. and Lawrence, R.L. (2009) Spectrally based remote sensing of river bathymetry. Earth Surf. Process. Landforms 34, 1039-1059.

Marlow, D.R., Beale, D.J. and Burn, S. (2010) A pathway to a more sustainable water sector: sustainability-based asset management. Water Science and Technology 61(5), 1245-1255.

Marlow, D., et al. (2011) A framework for considering externalities in urban water asset management. Water Science and Technology 64(11), 2199-2206.

Nazarbayev, N. (2013) Draft Decree of the President of the Republic of Kazakhstan on the State Program on Water Management of the Republic of Kazakhstan for 2014-2040. Government of Kazakhstan, Astana.

Stathakis, D. and Vasilakos, A. (2006) Comparison of computational intelligence based classification techniques for remotely sensed optical image classification. IEEE Transactions on Geoscience and Remote Sensing 44(8), 2305-2318.

Ubbels, A. and Verhallen, A.J.M. (2001) Collaborative planning in integrated water resources management: the use of decision support tools. Integrated Water Resources Management 272, 37-43.

Wang, X., et al. (2009) An eco-environmental water demand based model for optimising water resources using hybrid genetic simulated annealing algorithms. Part I. Model development. Journal of Environmental Management 90(8), $2628-2635$.

Yang, M.D. and Yang, Y.F. (2004) Genetic algorithm for unsupervised classification of remote sensing imagery. Image Processing: Algorithms and Systems 5298, 395-402. 